\title{
Effect of condensed tannins in Dorycnium rectum on its nutritive value and on the development of sheep parasite larvae
}

\author{
G.C. WAGHORN and A.L. MOLAN \\ AgResearch, Grasslands, Private Bag 11008, Palmerston North \\ garry.waghorn@agresearch.co.nz
}

\begin{abstract}
Sheep and laboratory trials have been undertaken to evaluate the potential value of Dorycnium rectum (Erect Dorycnium) for controlling gastrointestinal parasites. This perennial shrub grows to $3-4 \mathrm{~m}$ and can be cut or used as a browse forage. The leaves contain condensed tannin (CT) at about $20 \%$ of the dry matter (DM). Sheep were fed $D$. rectum to determine its digestibility and the effects of $\mathrm{CT}$ upon digestion. DM digestibility was $59.6 \%$ and increased to $63.6 \%(\mathrm{P}<0.05)$ when the effects of $\mathrm{CT}$ were removed, with comparable values of $23.6 \%$ and $73.6 \%$ for nitrogen $(\mathrm{N})$ digestibility. Condensed tannin was extracted from $D$. rectum to evaluate its in vitro effects on egg hatching and larval development of the gastrointestinal parasites Trichostrongylus colubriformis and Ostertagia circumcincta. Very low concentrations $(200 \mu \mathrm{g} / \mathrm{ml})$ reduced egg hatching and virtually halted maturation to the infective third larval (L3) stage. Although the CT in D. rectum reduced its nutritive value for sheep when fed as a sole diet, the inhibition of larval development in vitro suggests a possible role for disrupting the cycle of reinfection in grazing sheep.
\end{abstract}

Keywords: condensed tannins, digestibility, Dorycnium rectum, intestinal parasites, sheep

\section{Introduction}

Dorycnium rectum is a perennial legume shrub originating from moist areas of the Mediterranean region. It grows to 3-4 $\mathrm{m}$ in height and although capable of moderate DM yields (Douglas \& Foote, 1994), sheep only eat leaf and soft portions of stems. Experimental feeding suggests moderate palatability for sheep when fed fresh or pelleted, despite high concentrations of condensed tannins.

Our interest in $D$. rectum originated from the potential of some sources of CT to reduce the effects of gastrointestinal parasitism in sheep. Field trials have shown that sheep fed lotus (Lotus corniculatus, L. pedunculatus) or sulla (Hedysarum coronarium) were able to maintain good levels of productivity in the presence of gastrointestinal $T$. colubriformis and O. circumcincta worms, relative to worm-free (drenched) controls. This contrasted with poor performance of parasitised sheep fed white clover pasture or lucerne (Robertson et al. 1995). When sheep have been fed sulla, worm numbers have been reduced relative to sheep fed lucerne or to the pre-treatment control animals (Niezen et al. 1995; Robertson et al. 1995) but this was not the case with lotus (Robertson et al. 1995). Some of the differences between forages may be explained by the type of CT, as well as the concentration in the plant DM. In vitro assays have shown increased concentrations of CT progressively inhibiting the motility of $T$. colubriformis L3 larvae (Molan et al. 2000) but the extent of inhibition differed for the sources of CT. Condensed tannins extracted from lotus, sulla and Rumex obtusifolius (dock), have also reduced egg viability and larval development in vitro (Molan et al. 1999).

Our interest in forages having anti-parasitic properties is not intended to supplant proprietary anthelmintics, rather to facilitate control through various stages of the infective cycle. This might include reductions in egg production, egg hatching, larval viability and the ability of the L3 larvae to establish in the host. We are aware that the high concentration of CT in D. rectum leaves may reduce acceptability and have poor nutritive value for sheep, but we are not aware of published data concerning the digestibility of this forage by sheep. Results from two trials are presented here. Sheep were held in metabolism crates and fed $D$. rectum with and without daily oral administration of polyethylene glycol (PEG) to measure digestibility and effects of CT upon digestion. Condensed tannin extracted from $D$. rectum was added to eggs from two species of gastro-intestinal parasite to determine effects upon hatching and larval development.

\section{Methods}

\section{Nutritional aspects}

Nutritional aspects were undertaken in November using 12 young (15-month) Romney wether sheep. These were selected from an initial group of 16 on the basis of their behaviour in metabolism crates and drenched with anthelmintic prior to the commencement of the trial. 
The 12 sheep were randomly allocated to treatment groups and offered D. rectum ad libitum as a sole diet (control group) or with twice daily oral drenches of PEG (120g/day in water). The PEG preferentially binds with CT in vivo (e.g., Stienezen et al. 1996) and in vitro to negate effects of CT (Jones \& Mangan, 1977). All sheep were weighed at the commencement of the feeding trial and 14 days later at its conclusion.

D. rectum was cut with a sickle bar mower $30 \mathrm{~cm}$ above the ground to give stems $60-100 \mathrm{~cm}$ in length. Harvesting was daily at about $0830 \mathrm{~h}$, with sheep receiving their morning and afternoon feeds at about 0930 and $1700 \mathrm{~h}$. The forage for afternoon feeding was held at $4^{\circ} \mathrm{C}$. Stems which had been stripped of leaves were removed from bins throughout the day and early evening enabling sheep to maintain access to leaves and soft stems. Forage was given ad libitum as far as practicable, but rejection of thick stem (over 4-6 mm in diameter) made true ad libitum feeding difficult to achieve. Excess availability would have been impractical and may have affected the proportions of leaf and stem consumed. Feed offered and refused was weighed and subsampled for chemical analyses.

Animal measurements included daily feed intakes, digestibility and rumen ammonia and volatile fatty acid concentrations. Feed intakes were measured daily over the trial and faecal output (into faecal collection bags) was determined over the final 8 days. Samples of rumen digesta were obtained 1 and $5 \mathrm{~h}$ after the morning feeding on days 8 and 14 of the trial for ammonia and VFA analyses. Chemical analyses were similar to those described for sheep fed sulla by Stienezen et al. (1996).

\section{Gastrointestinal parasite assays}

In vitro assays of $\mathrm{CT}$ extracted from $D$. rectum were carried out using $O$. circumcincta and $T$. colubriformis eggs. The CT was extracted from $D$. rectum leaf with 70:30 acetone:water, cleaned by washing with methylene chloride and the extract purified by washing through Sephadex LH-20 (Pharmacia, Uppsala, Sweden) resin as described by Jackson et al. (1996). The freeze-dried extracts were added to egg hatching and larval development media to give 7-9 concentrations between 0 and 900 and 0 and $500 \mu \mathrm{g} \mathrm{CT} / \mathrm{ml}$ for the respective assays. Egg hatching assays were carried out in $2 \mathrm{ml}$ of media and larval development in $200 \mu 1$ in 48 or 96 well microtitre plates respectively, using methods described by Molan et al. (1999).

Eggs from the two nematode species were recovered from faeces of sheep infected with pure strains of each parasite. Samples of $50 \mathrm{~g}$ of faeces were mixed with water and eluted through progressively finer sieves enabling eggs to be retained on a $20 \mu \mathrm{m}$-aperture mesh.
They were washed to remove debris and held at a concentration of about 1600 per $\mathrm{ml}$ at $4^{\circ} \mathrm{C}$ until required.

The egg-hatching assay involved incubation of about 100 eggs in $2 \mathrm{ml}$ of distilled water containing 0,100 , 200, 400, 600 and $900 \mu \mathrm{g} \mathrm{CT} / \mathrm{ml}$. Each concentration of CT was incubated in triplicate at $24^{\circ} \mathrm{C}$ for $26 \mathrm{~h}$ and the number of hatched and unhatched eggs counted (Molan et al. 1999). The larval development assay was carried out in a culture medium (Hubert and Kerboeuf, 1984) containing 0, 25, 50, 100, 150, 200, 300,400 and $500 \mu \mathrm{g} \mathrm{CT} / \mathrm{ml}$ to which were added about 100 eggs. All assays were carried out in duplicate (quadruplicate for $0 \mathrm{CT}$ samples) by incubating at $24^{\circ} \mathrm{C}$ for 7 days after which the numbers of unhatched eggs and L1, L2 and L3 larvae were counted (Molan et al. 1999).

\section{Results}

$D$. rectum has a high proportion of leaf on the upper portions of stems, with decreasing proportions toward the ground. The material offered to sheep in this study comprised approximately 50\% leaf (DM basis) but the proportion of leaf eaten was much higher. The sheep were offered an average of $1580 \mathrm{~g} \mathrm{DM} /$ day with refusals of $460-580 \mathrm{~g}$ DM indicating the quantity of stem in the material offered. The average DM percentage of D. rectum over the digestibility period was $19.8 \pm \mathrm{SD}$ 1.06 , whilst the stemmy refusals contained about $22.5 \%$ DM. The leaves contained substantially more crude protein and CT than the stem (Table 1) which had a high proportion of structural fibre.

Table $₫ 1$ Chemical composition ( $\mathrm{g} / 100 \mathrm{~g}$ dry matter) of leaf, stem and whole plant Dorycnium rectum.

\begin{tabular}{lccc}
\hline & Leaf & Stem & Whole plant \\
\hline Nitrogen & 3.0 & 0.8 & 1.6 \\
Soluble carbohydrate & 19 & 2 & 12 \\
Lipid & 4.4 & 1.6 & 2.6 \\
NDF & 30 & 56 & 45 \\
ADF & 19 & 46 & 32 \\
Total CT & 20.1 & 6.2 & 13.4 \\
$\quad$ Unbound CT & 17.7 & 5.4 & 11.9 \\
Protein bound CT & 2.1 & 0.7 & 1.4 \\
Fibre bound CT & 0.3 & 0.1 & 0.1 \\
\hline
\end{tabular}

Abbreviations: NDF, neutral detergent fibre; ADF, acid detergent fibre; $C T$, condensed tannin

Feed intakes of 1005 and $1116 \mathrm{~g} \mathrm{DM} /$ day for the control and PEG treatments respectively, suggest reasonable acceptability of the forage despite the low DM digestibility (Table 2). Both DM intake and digestibility were highest for sheep receiving PEG $(\mathrm{P}<0.002)$ suggesting a negative impact of $\mathrm{CT}$ upon 
nutritive value. This was more apparent when nitrogen digestibility was compared; the very low value of $23.6 \%$ in control sheep contrasted with $73.6 \%$ when PEG was given (Table 2).

Metabolite concentrations in rumen digesta confirm the effects of CT, with control sheep having much lower ammonia concentrations than those given PEG $(\mathrm{P}<0.001$; Table 2). The concentrations of VFA were also lower in control sheep (Table 2) but molar proportions were similar for the two treatments, with acetate:propionate:butyrate ratios of 74:15:9 for control and 71:16:9 for PEG animals. Only the minor VFA showed significant $(\mathrm{P}<0.005)$ treatment differences (molar \% of total VFA) for control (2.44\%) and PEG (3.38\%) sheep.

In the absence of CT, $87 \%$ of $O$. circumcincta and $92 \%$ of $T$. colubriformis eggs hatched and although increasing concentration of $\mathrm{CT}$ reduced hatching, $70 \%$ and $63 \%$ of eggs hatched when CT concentration was $400 \mu \mathrm{g} / \mathrm{ml}$ (Figure 1a). Further increases in CT concentration up to $900 \mu \mathrm{g} / \mathrm{ml}$ reduced hatching percentage $(\mathrm{P}<0.001)$.

Egg development to the L3 stage, was $89 \%$ for O. circumcincta eggs and $86 \%$ for T. colubriformis eggs without $\mathrm{CT}$, but when the media contained $100 \mu \mathrm{g}$ $\mathrm{CT} / \mathrm{ml}$ only $39 \%$ and $28 \%$ of eggs from the respective species attained full development after 7 days (Figure 1b). Increasing CT concentration to $200 \mu \mathrm{g} / \mathrm{ml}$ reduced development of the respective species to $8 \%$ and $4 \%$ respectively and $300 \mu \mathrm{g} \mathrm{CT} / \mathrm{ml}$ prevented development of $T$. colubriformis past the L1 larval stage. There was no development of $O$. circumcincta beyond the L1 stage with $400 \mu \mathrm{g} \mathrm{CT} / \mathrm{ml}$.

\section{Discussion}

The feeding trial has shown that sheep will eat sufficient $D$. rectum for maintenance but that the $\mathrm{CT}$ severely inhibits nitrogen utilisation and limits nutritive value. This limitation is removed by neutralising the CT with PEG. However, low concentrations of CT limited the development of larvae from two important gastrointestinal parasites under in vitro conditions. These results pose two questions: will the inhibition of larval development occur under field conditions, and if so to what extent could the CT in D. rectum be diluted with other forages whilst retaining any effectiveness against gastrointestinal parasites? These findings support in vitro effects of CT from sulla (Molan et al. 1999; 2000) which also reduced faecal egg counts (FEC) when fed to sheep (Niezen et al. 1995; Robertson et al. 1995) but $D$. rectum would be fed with other forages to dilute the negative nutritional effects of CT. If D. rectum could
Figure $\llbracket 1$ (A) The effect of condensed tannins (CT) extracted from Dorycnium rectum on the proportion of Ostertagia circumcincta and Trichostrongylus colubriformis eggs hatched in vitro. Each point represents the mean of triplicate incubations with the standard error of the mean. (B). The development of Ostertagia circumcincta and Trichostrongylus colubriformis eggs to infective L3 larvae in the presence of condensed tannins (CT) extracted from Dorycnium rectum. Each point represents the mean of duplicate incubations with the standard error of the mean.
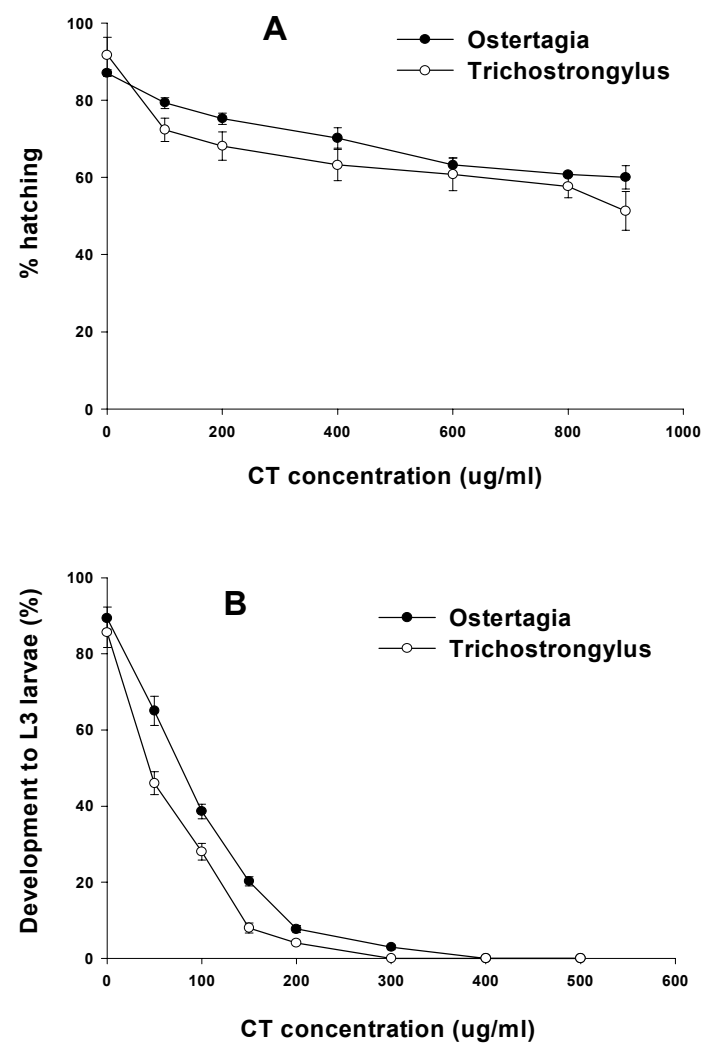
complement pasture feeding, the lower concentration of $\mathrm{CT}$ in a mixed diet would protect pasture proteins from excessive ruminal degradation and may lower egg viability. An improved protein supply to the small intestine may facilitate an immune response to parasitism and improve animal performance (e.g., Waghorn et al. 1998), so complementarity between pasture and forages containing CT might have multiple advantages for animals.

The concentration of CT used in egg hatching and larval development assays was much lower than concentrations of CT in faeces. In this trial, the DM digestibility of the $D$. rectum was $57 \%$, so the dietary CT would have passed into $43 \%$ of the DM consumed. As the CT is not absorbed, a dietary concentration of $15 \%$ would have increased to approximately $35 \%$ of faecal DM or $100 \mathrm{mg} / \mathrm{g}$ of faecal wet matter. This is far higher than the $400 \mu \mathrm{g} / \mathrm{ml}$ able to prevent larval development in vitro, but care must be taken when extrapolating from in vitro to in vivo conditions because some changes occur in CT during digestion (Terrill et al. 1994) and may reduce its impact upon larval development. Furthermore, a sheep having faecal egg counts of 700/g will produce about one million eggs per day and a substantial number are likely to survive the effects of CT so it is important to evaluate the effects of $D$. rectum fed to parasitised sheep on egg and larval viability.

The effects of the CT upon the nutritive value of D. rectum will prevent liveweight gain after feeding as a sole diet for more than a few days. It is therefore, essential that $D$. rectum be fed with other forages, but we have no information concerning the extent to which the $\mathrm{CT}$ can be diluted and retain anti-parasitic properties. Research with CT from other forages has shown both concentration and type (source) affect nutritional value (Waghorn et al. 1998), animal performance in the presence of parasitism (Robertson et al. 1995), egg development in vitro (Molan et al. 1999) and larval migration in vitro (Molan et al. 2000). The effect of CT in D. rectum when fed as a mixed diet can only be determined in animal trials.

A major challenge for researchers would be to ensure that $D$. rectum is eaten by sheep when high quality pasture is available. Observations by Douglas (unpublished) have shown about $70 \%$ of accessible leaves were eaten by sheep having access to average quality pasture. In contrast, limited observations with goats suggest $D$. rectum is extremely palatable to these animals and the forage would be readily accepted with pasture. Research needs to be undertaken to evaluate these opportunities for parasite control in field trials with sheep and goats using forage mixtures including D. rectum to achieve a range of $\mathrm{CT}$ concentrations in the diet.

\section{ACKNOWLEDGEMENT}

Thanks to Emma Bermingham for assistance with animal aspects of this experiment.

\section{REFERENCES}

Douglas, G.B.; Foote, A.G. 1994. Establishment of perennial species useful for soil conservation and as forages. New Zealand Journal of Agricultural Research 37: 1-9.

Hubert, J.; Kerboeuf, D. 1984. A new method for culture of larvae used in diagnosis of ruminant gastrointestinal strongylosis: comparison with faecal cultures. Canadian Journal of Comparative Medicine 48: 63-71.

Jackson, F.S.; McNabb, W.C.; Barry, T.N.; Foo, Y.L.; Peters, J.S. 1996. The condensed tannins of a range of subtropical and temperate forages and the reactivity of condensed tannin with ribulose-1,5-bisphosphate carboxylase (Rubisco) protein. Journal of the Science of Food and Agriculture 72: 483-492.

Jones, W.T.; Mangan, J.L. 1977. Complexes of the condensed tannins of sainfoin (Onobrychis viciifolia Scop.) with fraction 1 leaf and with submaxillary mucoprotein, and their reversal by polyethylene glycol and pH. Journal of Science of Agriculture 28: 126-136.

Molan, A.L.; Waghorn, G.C.; McNabb, W.C. 1999. Condensed tannins and gastro-intestinal parasites in sheep. Proceedings of the New Zealand Grassland Association 61: 57-61.

Molan, A.L.; Waghorn, G.C.; Min, B.R.; McNabb, W.C. 2000. The effect of condensed tannins from seven herbages on Trichostrongylus colubriformis larval migration in vitro. Folia Parasitologica 47: 39-44.

Niezen, J.H.; Waghorn, T.S.; Charleston, W.A.G.; Waghorn, G.C. 1995. Growth and gastrointestinal nematode parasitism in lambs grazing either lucerne (Medicago sativa) or sulla (Hedysarum coronarium) which contains condensed tannins. Journal of Agricultural Science, Cambridge 125: 281-289.

Robertson, H.A.; Niezen, J.H.; Waghorn, G.C.; Charleston, W.A.G.; Jinlong, M. 1995. The effect of six herbages on liveweight gain, wool growth and faecal egg count of parasitised ewe lambs. Proceedings of the New Zealand Society of Animal Production 55: 199-201.

Stienzen, M.; Waghorn, G.C.; Douglas, G.B. 1996. Digestibility and effects of condensed tannins on digestion of sulla (Hedysarum coronarium) when fed to sheep. New Zealand Journal of Agricultural Research 39: 215-221. 
Terrill, T.H.; Waghorn, G.C.; Woolley, D.J.; McNabb, W.C.; Barry, T.N. 1994. Assay and digestion of ${ }^{14} \mathrm{C}$-labelled condensed tannins in the gastrointestinal tract of sheep. British Journal of Nutrition 72: 467-477.

Waghorn, G.C.; Douglas, G.B.; Niezen, J.H.; McNabb, W.C.; Foote, A.G. 1998. Forages with condensed tannins - their management and nutritive value for ruminants. Proceedings of the New Zealand Grassland Association 60: 89-98. 